\title{
International recruitment of health professionals
}

\author{
We need to identify effective approaches to managing and moderating migration
}

$\mathrm{F}$ or the United Kingdom, and some other developed countries, active international recruitment has become a solution to shortages of health professionals. However, one country's solution may become another's problem. The recent House of Commons report on migration and development ${ }^{1}$ and other commentators have highlighted the negative impact of international recruitment on the health systems of some of the main source countries, particularly in sub-Saharan Africa. ${ }^{2}$ The issue of migration of health professionals has become an important feature of international health policy debate symbolised by the passing of a resolution at the World Health Assembly.

How important is international recruitment to the NHS? Estimates of the inflow of doctors to the United Kingdom can be derived from the registration records of the General Medical Council. Registration data highlight a recent upsurge in inflow of doctors to the United Kingdom. In 2002, nearly half of the 10000 new full registrants on the GMC register were from overseas; in 2003 this had risen to more than two thirds of a total of 15000 . Most of the growth has been in entrants from countries outside the European Economic Area.

International recruitment offers the prospect of a quick fix, with the import of ready made doctors, who would otherwise take 10 years or more to train if the "grow your own" option was selected. The Department of Health in England has been explicit in its support for international recruitment. It has issued a code of practice, ${ }^{4}$ which requires NHS employers not to recruit actively from developing countries, unless an agreement between the two governments has been made. It also lists approved recruitment agencies. Critics highlight the code that has not ended the inflow of health professionals from the "proscribed" countriesfor example, in 2003, one in three work permits issued to nurses were to applicants who came from these developing countries, mainly in sub-Saharan Africa. ${ }^{5}$

Various recruitment routes are not proscribed by the code. These include entrants coming to the United Kingdom for purposes of education rather than employment, individual health workers taking the lead to apply for jobs in the United Kingdom, and some staff actively being recruited by non-NHS employers. Quantifying the relative contribution of each of these components of inflow is not possible with the current data-a limitation that was highlighted by the House of Commons report.

England was the first country to have introduced a detailed code on international recruitment of health workers (box). The Commonwealth has also introduced guidelines, ${ }^{6}$ as have some international associations for health professionals have also promoted codes and principles for international recruitment, but these are not binding and reflect mainly aspiration. ${ }^{7}$

Migration of health professionals is likely to remain on the policy agenda. Push factors of low pay and relatively limited career opportunities for health professionals will continue to have an impact in many developing countries, just as pull factors related to skills shortages will persist in many developed countries. Any country affected by in or out migration has two possible policy stances. Non-intervention ("let the market rip") or some degree of intervention to attempt to manage the migration process. The latter is what is being advocated by the World Health Assembly. Some of the possible interventions include bilateral agreements between countries, staff exchanges, and regional initiatives of managed migration. ${ }^{89}$

These interventions are largely untested. They require to be evaluated to identify which, if any, have the potential for mutual and beneficial impact. The debate on the migration of health workers must shift from an obsession with numbers (how many?) to identifying effective approaches to managing and moderating the process (how?). Even so, issues that are more fundamental need to be addressed. Health professionals should have the right to move-or stay. Although their migration is often characterised as a problem, it can also be a symptom of a deeper malaise in the human resource component of some health systemsplanning failures, the inability (or unwillingness) to pay fairly, and lack of career prospects. Migration of health workers should not be addressed in isolation; it has to be assessed as an integral part of the overall dynamics of the healthcare labour market.

James Buchan professor

Health and Social Sciences, Queen Margaret University College, Edinburgh EH12 8TS

(jbuchan@qmuc.ac.uk)

Competing interests: None declared.

1 House of Commons International Development Committee. Migration and development: how to make migration work for poverty reduction. Sixth report of session 2003-4. London: Stationery Office, 2004. (HC-79-1.)

2 Physicians for Human Rights (2004). An action plan to prevent Brain drain: building equitable health systems in Africa. Boston: Physicians for Human Rights, 2004.

3 World Health Organization. Agenda item 12.11. Fifty Seventh World Health Assembly: health systems including primary care. International migration and health personnel: a challenge for health systems in developing countries. 22 May 2004. Geneva: World Health Organization, 2004.

4 Department of Health. Code of Practice for the international recruitment of healthcare professionals: December 2004. London. http:// www.dh.gov.uk/PolicyAndGuidance/HumanResourcesAndTraining/ MoreStaff/InternationalRecruitmentNHSEmployers/

CodeOfPracticeArticle/fs $/$ en?CONTENT ID $=4043625 \&$ chk = D2OJCV (accessed 21 December 2004).

5 Buchan J. Dovlo D. International recruitment of health workers to the UK: a report for DFID.2004. London: Department for International Developreport for DFID.2004. London: Department for International Develop-
ment Resource Centre, 2004. www.dfidhealthrc.org/shared/ publications/reports/int_rec/int-rec-main.pdf (accessed $27 \mathrm{Jul}$ 2004).
Commonwealth Secretariat. Commonwealth code of practice for international recruitment of health workers. London: Commonwealth Secretariat, 2003. 7 World Organization of National Colleges, Academies and Academic Associations of General Practitioners/Family Physicians. (WONCA). A code of practice for the international recruitment of health professionals: the Melbourne manifesto. 2002. World Organization of National Colleges, Academies and Academic Associations of General Practitioners Family Physicians. www.ruralhealth2002.net/melbourne_manifesto.pdf (accessed 9 Mar 04)

8 Department of Health. International humanitarian and health work toolkit to support good practice, and compendium of the NHS's contribution to developing nations. London: $\mathrm{DoH}, 2003$.

9 Yan J. Caribbean nurses develop strategy for nurse shortages. Int Nurs Rev 2002:49:132-4. 